Diyala Journal of Engineering Sciences

Journal homepage: https://en.enginmag.uodiyala.edu.iq/

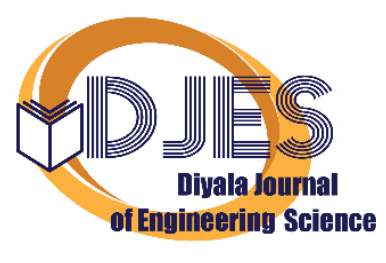

ISSN: 1999-8716 (Print); 2616-6909 (Online)

\title{
Modelling of Groundwater Flow of Baquba District Area, Diyala Governorate, North-East, Iraq
}

\author{
Sufyan M. Jasim, Qassem H. Jalut* \\ Department of Civil Engineering, College of Engineering, University of Diyala, 32001 Diyala, Iraq
}

ARTICLE INFO ABSTRACT

\section{: Article history}

Received 18 July 2019

Accepted 17 November 2019

\section{Keywords:}

Baquba district area; Groundwater modeling; GMS software; Quaternary sediments; Conceptual model; Calibration.

\begin{abstract}
Groundwater is one of the important water resources in the countries that have a scarcity in water resources such as surface water. Modeling of the Baquba shallow unconfined aquifer (Quaternary sediments) has been an attempt by transfer the conceptual model to GMS 10.0-MODFLOW2000 for solving the groundwater equations by the technique of finite-difference. Two types of boundary conditions have been applied (Neumann and Dirichlet conditions). The calibration of the model has been attempt based on adjusting two parameters hydraulic conductivity and recharge rate. The best matching between computed and observed head has been done. The results reflect that the sensitivity analysis shows that hydraulic conductivity and recharge rate are a more sensitive parameter, after calibration, six different scenarios have investigated to study the impact of the discharging rate on the groundwater state. In the five scenarios, the applying discharge rates in the current state and increased by $(25 \%, 50 \%, 75 \%$ and $100 \%)$ successively above the current rate, while in the sixth scenario proposed agricultural land with drilling new wells. The stress period that has been applied in transit state extended from (2018-2027) with ten-time steps. The unsteady-state model simulation results for these scenarios clarify that the annual maximum drawdown values have been observed for the next ten years according to the five scenarios are equal to $(11.426,11.938,12.246,13.631$, and 14.05$) \mathrm{m}$ respectively, while the annual maximum drawdown value recorded in the proposed scenario (current rate with the rates of the new wells) equal to $11.87 \mathrm{~m}$. As well as this increases in discharging rates indicated that the possibility of drilling new wells within the study area without any mining of aquifer. The results of the model reflect that the maximum values of the drawdown for the two regions of (Kanan and Buhriz) are very large, and according to this reason the management program is very important for dealing and manage the groundwater extraction in these regions.
\end{abstract}

\section{Introduction}

The essential part of all creatures to stay on alive is water. Due to the high need for water in the last years, in order to use for various purposes such as irrigation, industrial and others, both of the surface water and groundwater has been played an important role as one of the vital sources in the provision of water [1] and [2]. In many regions the quantity of the groundwater is large and influential so the groundwater resource, in this case, shall be considered from the hydrologic side as well as water resources management [3]. Usually, the activities of the human's and normal operations have been effected on the groundwater systems with some reasonable degree, for that its need more careful management and maintenance with permissible limits for the purposes of

${ }^{*}$ Corresponding author.

E-mail address: qjalut@gmail.com

DOI: $10.24237 /$ djes.2020.13302 
economic and social benefits from this resource. However, the pre and present knowledge of the groundwater behavior should be as a base for understanding the future changing [4]. One of the important tools for water resources assessment and management is by applying computer models, this is due to the efficiency and quality of these models to help decision maker to selecting the suitable alternative for managing the groundwater resources with some constraints [5]. The important things for management the groundwater are attempt by prediction of subsurface flow, solute transport, water table, and simulation the stresses caused by human (human- activity) [6]. The suitable and appropriate strategies related to the management of the groundwater under the climate change and hydrologic cycle variance with different years are attempt by groundwater modeling [7]. It's essential to select suitable software for modeling according to the area conditions in order to achieve the requirements of modeling [8].

The groundwater models are classified as three types: mathematical, physical and analogue models. The most famous and popular model is the mathematical model that opens the way to solve groundwater state either by numerical or analytical methods. The analytical method doesn't require high complexity of the data and it has been adopted for simple cases. While the numerical method has been powerful for solving the complex problems and deal perfectly with it, these methods became the most usable way because of the modern revolutions of the computer's development and its high processers speed. The finite difference and finite element methods are the most popular that has been used for modeling the groundwater systems and each method has advantage and limitations. The modeling type selection and methods depend on the type and the complexity degree of the problem that we need to simulate or solve it [9]. One of the best software applied by the researchers is the model invented by a geological survey of the United States of America that have the name of MODFLOW [10].

The study area is within Diyala governorate in the city of Baquba in the northeast part of Iraq, this city has large human activity from different sides including the commercial and industrial activities. Hence, and according to this growth of the city, the consumption of the water (groundwater) became very large, so it is important to study the groundwater use in a good manner. Based on these reasons, the main targets of this study are focusing on the effects of abstractions rates on the groundwater system and the need for the development of effective management strategies and regulations.

\section{Description of study area}

The coordinates of the study area are $33^{\circ} 25^{\prime}$ $26^{\prime \prime} \mathrm{N}$ and $33^{\circ} 53^{\prime} 24^{\prime \prime} \mathrm{N}$ latitudes and $44^{\circ} 23^{\prime}$ $17^{\prime \prime} \mathrm{E}$ and $44^{\circ} 57^{\prime} 47^{\prime}$ ' $\mathrm{E}$ longitudes as shown in Figure 1 and the area of the study have are equal to $1630 \mathrm{~km} 2$ with the height from the sea level between 26 to 55 meter. The topography of the study area is flat terrain with limited undulating topography. The climate of the study area is ranged from hot and dry through the summer season to cold and rainy in the winter season, the average value of annual precipitation of years from 1980-2014 is $100-200 \mathrm{~mm}$ [11]. For the quaternary sediment that is cover the area, it consists of clay, silt, silty clay, sand, and gravel [12]. The study area river includes sections has the names of Mehrut, Ruuz, and Khalis in the Muqdadiya, Baldruz and Khalis cities. The Diyala river has the major priority for irrigating wide areas of the Diyala province in spite of at the recent years the wells standing in the province for using in different purposes [13] and [14]. 


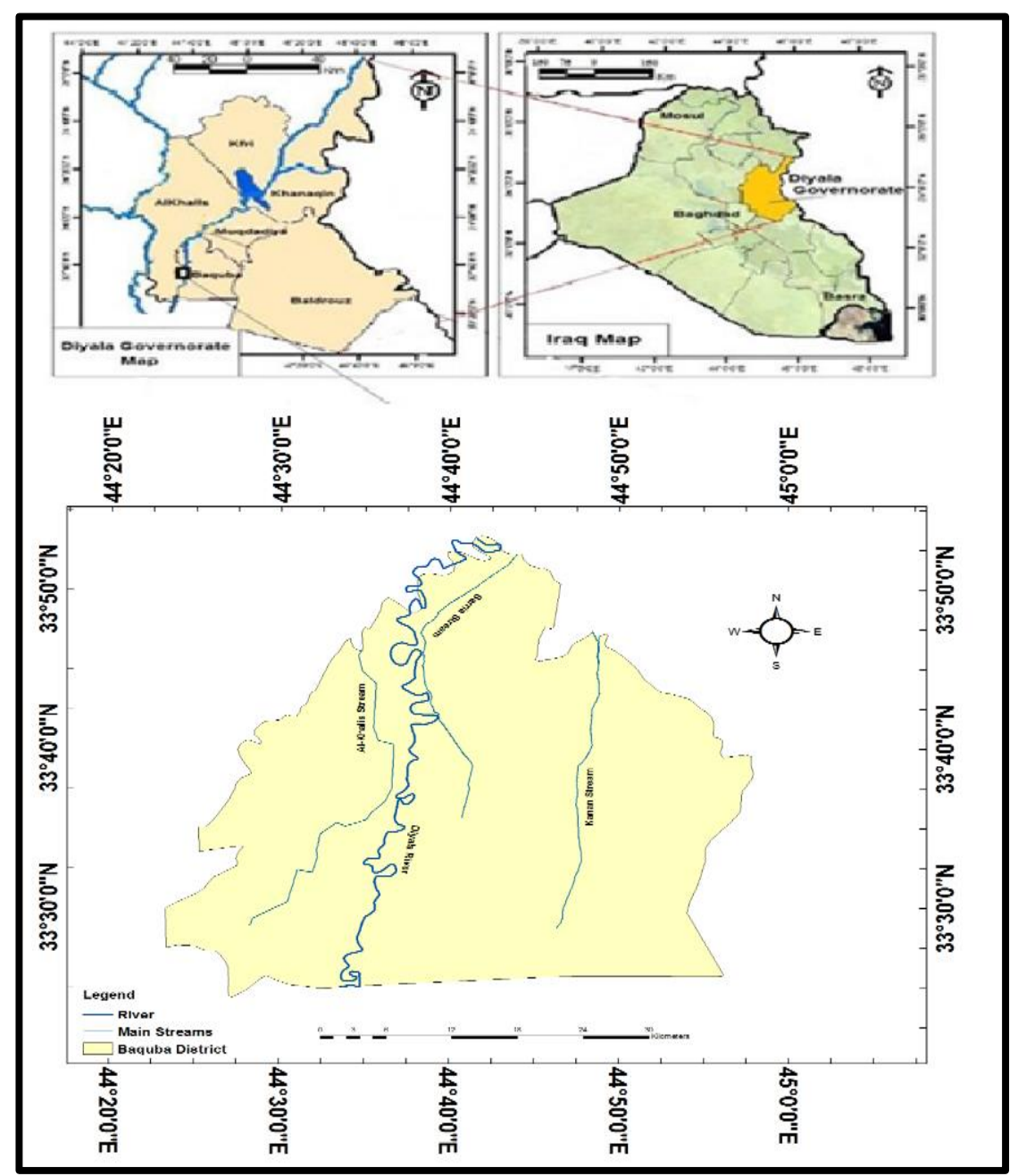

Fig. 1. Location map of the Baquba study area

\section{Groundwater flow equations}

The mathematical model of the groundwater based on Darcy law and it defines as the quantity (mass or momentum) passing through specific volume during a given time interval and the change amount of the volume storage quantity in equalizer state. The equation used for groundwater simulation through the porous media it expressed below [9]:

$$
\begin{gathered}
\frac{\partial}{\partial x}\left(\mathrm{~K} \mathrm{xx} \frac{\partial \mathrm{h}}{\partial x}\right)+\frac{\partial}{\partial y}\left(\mathrm{~K} \mathrm{yy} \frac{\partial \mathrm{h}}{\partial y}\right)+\frac{\partial}{\partial z}\left(\mathrm{~K} \mathrm{zz} \frac{\partial \mathrm{h}}{\partial z}\right) \\
\pm \mathrm{W}=S_{s} \frac{\partial h}{\partial t}
\end{gathered}
$$

In the above equation

Kxx: hydraulic conductivity in $\mathrm{x}$-direction measured by $(\mathrm{L} / \mathrm{T})$
Kyy: hydraulic conductivity in $\mathrm{y}$-direction measured by $(\mathrm{L} / \mathrm{T})$

Kzz: hydraulic conductivity in z-direction measured by $(\mathrm{L} / \mathrm{T})$

$\mathrm{h}: \quad$ is the (potentiometric head) measured by (L)

$\mathrm{w}$ : is a volumetric flux per unit volume representing sources \& sinks of water, with $\mathrm{W}<0$

for flow out of the groundwater system, and $\mathrm{W}>0$ for flow into the system (T-1).

$\mathrm{S}_{\mathrm{S}}$ : is the specific storage of the porous substance (L-1); and t: is time (T). 


\section{Collection date for model construction}

The required data needed for the construction of the mathematical model are classified as the following:

a. Groundwater level: the data of the groundwater level for an indicated the year of 2017 have been measured and recorded.

b. Drilling borehole logs: these data generally have been got from the Diyala groundwaterauthority.

c. Precipitation data: all related data of the precipitation have been gotten from Al-Khalismeteorological station with period extend (19802014).

d. Topographic data: the required data for describing the elevations of the study area haven represented by the digital elevation model DEM that has been provided from the United States Geological Survey (USGS) and downloaded from the website (https://earthexplorer.usgs.gov/).

Hydraulic related parameters: according to the pumping test process the initial values of hydraulic conductivity and specific storage have been gotten.

\section{Model selection and building study area model}

The GMS-MODEFLOW model (GMS10.0MODFLOW 2000) has been used in the present study due to the high efficiency. All the steps needed for groundwater modeling has been provided in this model (software), these steps incudes site-characterizations, development of the model, calibration with both way manually and automatically as well as visualization and post-processing. The GMS support different models that have been based on the finiteelements and finite-difference with both two dimensions and three dimensions such as (MODFLOW 2000, 2005, and NT, MODPATH, MT3DMS/RT3D, SEAM3D, ART3D, UTCHEM, FEMWATER and SEEP2D). The user can choose the tools and the model according to the requirement needed for solving his problem of modeling the groundwater [15]. For the present study, the conceptual-method has been selecting to be used. Two main steps have been used for construction GMS-model one of them is creating the model and another step is applying the calibration process for the created model. The groundwater modeling steps described in the following steps and demonstrated in Figure 2.

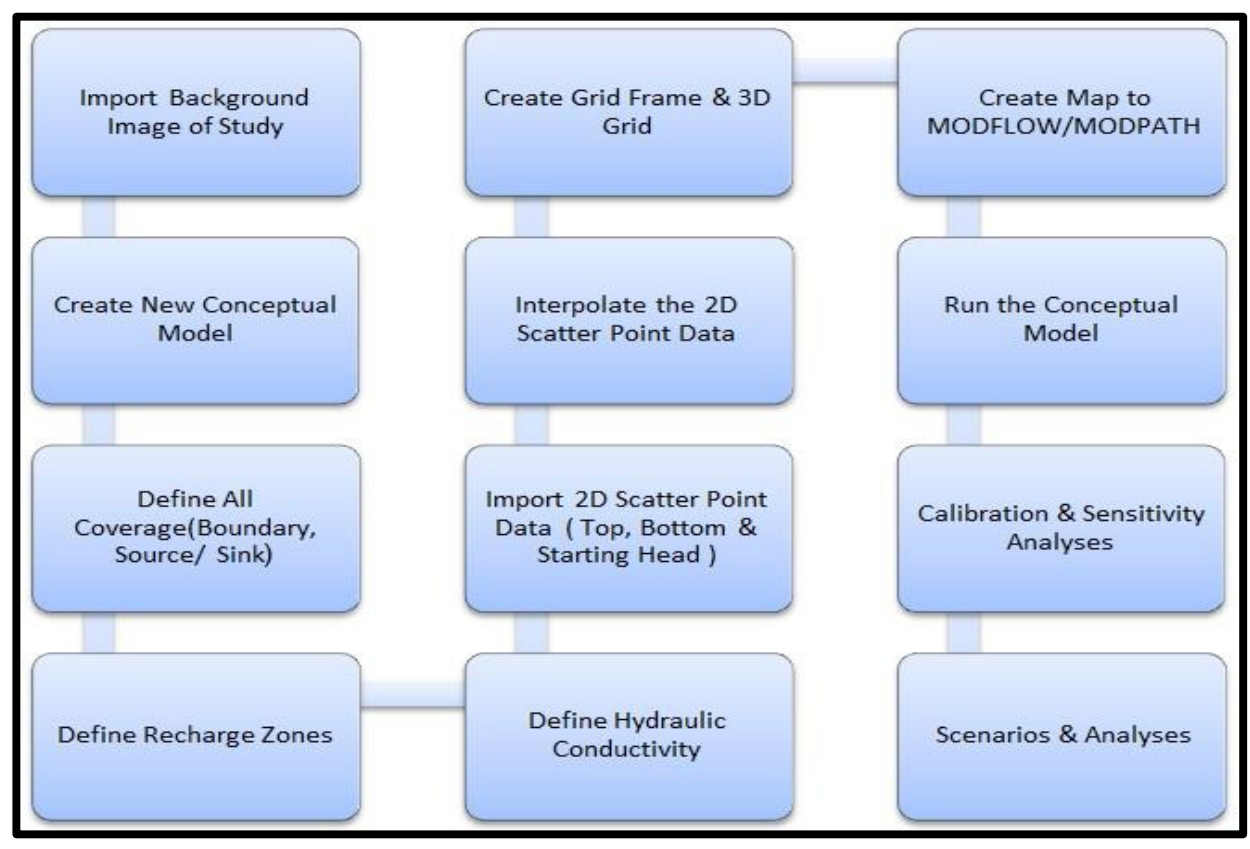

Fig. 2. Development of GMS-conceptual model flow-chart 


\subsection{Background image inserting}

The importing of the background image is the first step of model development. This image has been created by the GIS-processing of the DEM, the processing includes study area extracting by creating shapefile and clipped according to the boundary of the study area as well as projecting it then imported to the GMS and saved.

\subsection{Boundary condition}

These steps include defining the boundary for developing the conceptual model. The developing is based on the site characteristics such as rivers, stream, no flow etc. The model outer boundaries is attempted by creating an arc as a loop surrounding the site of the study and creating an arc to represent the others inner the boundaries.

\subsection{Creating locally source/ sink coverage}

The coverage source and sinks have been defined in this step. The coverage process includes defining the boundary area and the location of the wells.

\section{a. Boundary conditions}

All the directions boundaries include (Western, Eastern, Northern and Southern) defined as Neumann boundary condition (No Flow), while the boundary located at the middle classified and defined as Dirichlet boundary condition (specified head boundary) which is represented the Diyala-River.

\section{b. Creating the wells}

In the local source /sinks coverage, the entire modeled regions should be covered without any polygons overlapping. This is representing the grid of the active region. The default variable head polygons are considered the most case. However, the other polygons also may be used.

For example, a general head polygon has been used for lake modeling. After the processing of polygon construction, the text-file has been imported to the GMS that are containing the information of the well. The text file was created by using excel program to enroll the required information like coordinate of the well and pumping rate, the entered pumping rate values may have positive (injection) or negative(pumping) according to the type of the well in the study area. All the values of the rate have been negative.

\subsection{Creating recharge coverage}

The coverage recharge zone creating has been represented as the next step of the conceptual model construction. The no-flow boundaries have been surrounded by for side west, east, south, and north of the GMS model. That's restricted the flow to the well represented by the precipitation and recharge has happened only from the top surface. In the study area the recharge has been assumed to be uniform over bolegon with value between $(5-40) \%$ of the annual rainfall value. The GMS model calculated the recharge rate from:

Recharge $\left(\frac{m}{\text { day }}\right)=\frac{(\text { Annual rainfall }(m) \times 0.05)}{365}$

Based on this relation, the recharge rates have been equal to $(0.0000204 \mathrm{~m} /$ day $)$ from the annual rainfall $(148.8 \mathrm{~mm})$ for the rainfall period (1980-2014). This value used to run the model and for calibration process with steady state conditions.

\subsection{Defining hydraulic conductivity zones}

The coverage hydraulic conductivity $(\mathrm{K})$ is the next step of set up. In many cases, the hydraulic conductivity has been used to define the multiple polygons. In the present study, the area has been divided into eight zones based on the pumping locations and boundary conditions. In order to run of steady-state conditions, the initial value of $k$ has been set up, Table (1). The specific yield has been set through the unsteady state within this coverage. The set value is shown in Table (1). 
Table 1 Average of the hydraulic parameters according to the area of the wells locations

\begin{tabular}{|c|c|c|c|c|}
\hline Name of Location & $\begin{array}{c}\text { Average } \\
\mathbf{T}\left(\mathbf{m}^{2} / \mathbf{d a y}\right)\end{array}$ & $\begin{array}{c}\text { Average } \\
\mathbf{K}(\mathbf{m} / \mathbf{d a y})\end{array}$ & $\begin{array}{c}\text { Average } \\
\mathbf{S}_{\mathbf{c}}(\mathbf{L} / \mathbf{s e c})\end{array}$ & $\begin{array}{c}\text { Average } \\
\mathbf{S}_{\mathbf{y}}\end{array}$ \\
\hline Ghbinat-Alsawamira & 182.89 & 15.01 & 1.02 & 0.09 \\
\hline Al-Tahrir & 175.55 & 13.50 & 0.98 & 0.09 \\
\hline Abu-Khamis-Buhriz & 228.25 & 12.66 & 2.83 & 0.08 \\
\hline Al-Bardia-Al-muradia & 480.72 & 24.24 & 4.71 & 0.28 \\
\hline Al- Othmania-Baquba & 214.38 & 12.08 & 2.42 & 0.10 \\
\hline Bani-saad & 197.97 & 9.5 & 2.80 & 0.05 \\
\hline
\end{tabular}

\subsection{Creating the grid}

The first step in modeling has been an attempt by discretizing the area by using finite difference method. The accuracy of the model varies according to the varying in the size of the mesh or in other words the numbers of rows and column of the mesh; however, the high numbers of mesh squares reflect high accuracy of the models and vice -versa [16]. In the present study, the uniform fine grids have been constructed and the model area discretized in 200x200m grid cells. The total numbers of the cell and the area in the model is equal to 87320 cells, $1806.32 \mathrm{~km} 2$ respectively.

Consists of 295 rows and 296 columns; the total active and inactive cells are 45158, 42162 respectively. The conditions that show the types of cell are ( 1 for active cells, 0 for inactive and 1 for a constant head). Figure (2) has shown the grid design of the study area.

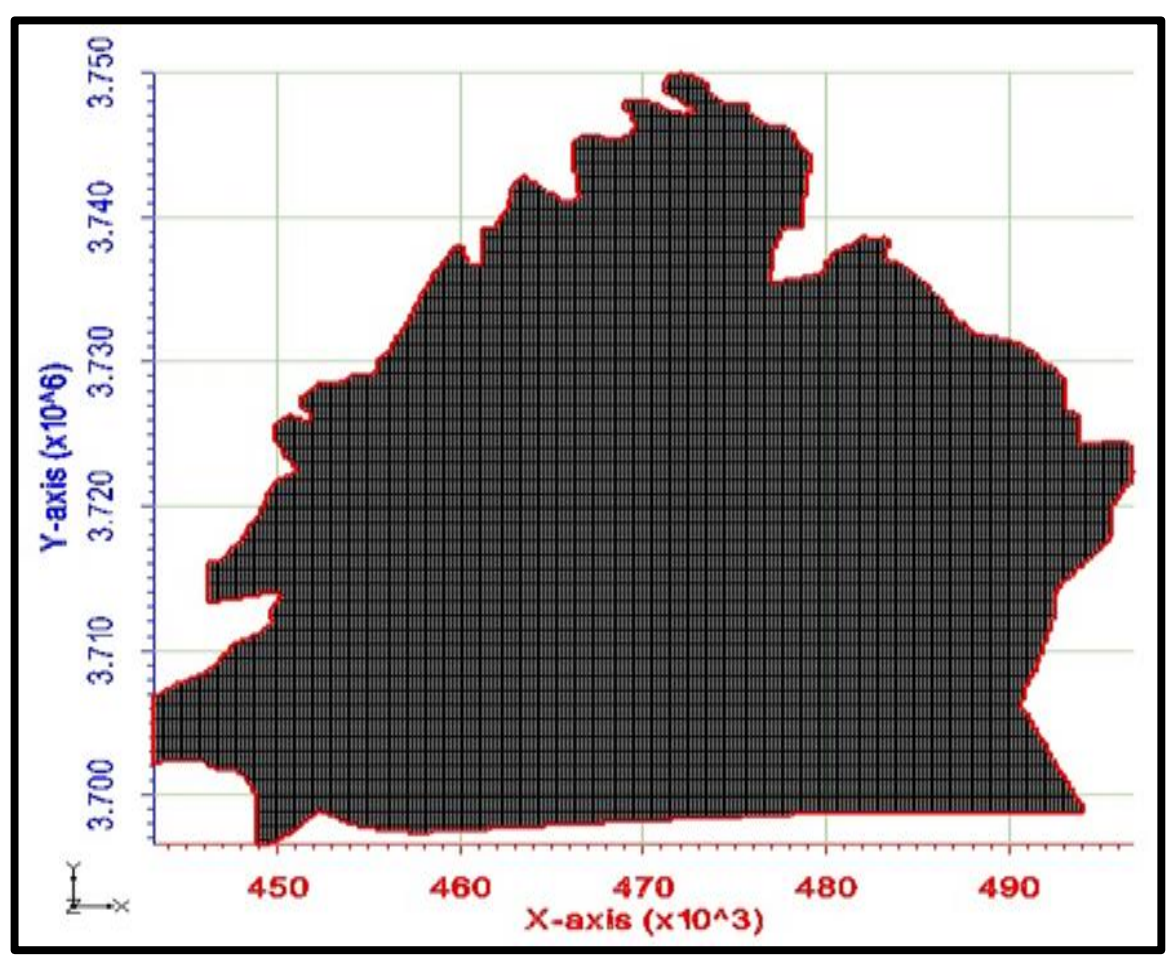

Fig. 3. Grid design of study area 


\subsection{Layer elevation}

The elevation layers creation is the final step of conceptual model development. In the present study, the single layer has been used to avoid the problem of the unknown Quaternary aquifer system zones and totally thickness. The digital elevation model DEM is the source of the top elevation that's ranged from $26-54 \mathrm{~m}$. The interpolated of the bottom elevation has been based on the boreholes depth. All of these data interpolated with the model layers of MODFLOW. The interpolated of the bottom elevation has been based on the boreholes depth. Also, the starting head has been interpolated with the layers of MODFLOW.

\subsection{Model calibration}

The calibration process has been attempt either manually or automatically, the automatic calibration includes the use of the optimization approach (optimization scheme) (PEST). It has been applied for both steady and unsteady state The target of the calibration is to reach a reasonable matching between the observed and simulated water head. In the current study, the threshold value of the head has been set equal to $0.5 \mathrm{~m}$ when the variation in the simulated water head less than or equal to $0.5 \mathrm{~m}$ then the simulated head will be acceptable. The adjusted variable includes both hydraulic conductivity and recharge rate. According to the concept of calibration of the groundwater mathematical model the static head level of the water in the pumping well has been observed.

When running the MODFLOW the target of the calibration has appeared in the observation well on the grid. The demonstration of the calibration target appears in Figure 4. The observation value represented by the center of the target. The top and the bottom of the target represent the observed value plus the interval and the observed value minus the interval respectively In the MODFLOW the box represent the error and will be drawn green when it was located at inside within the target and the box will be drawn yellow when the error less than $200 \%$ and located at the outside of the target, finally the box will be drawn red when the error greater than $200 \%$ [17].

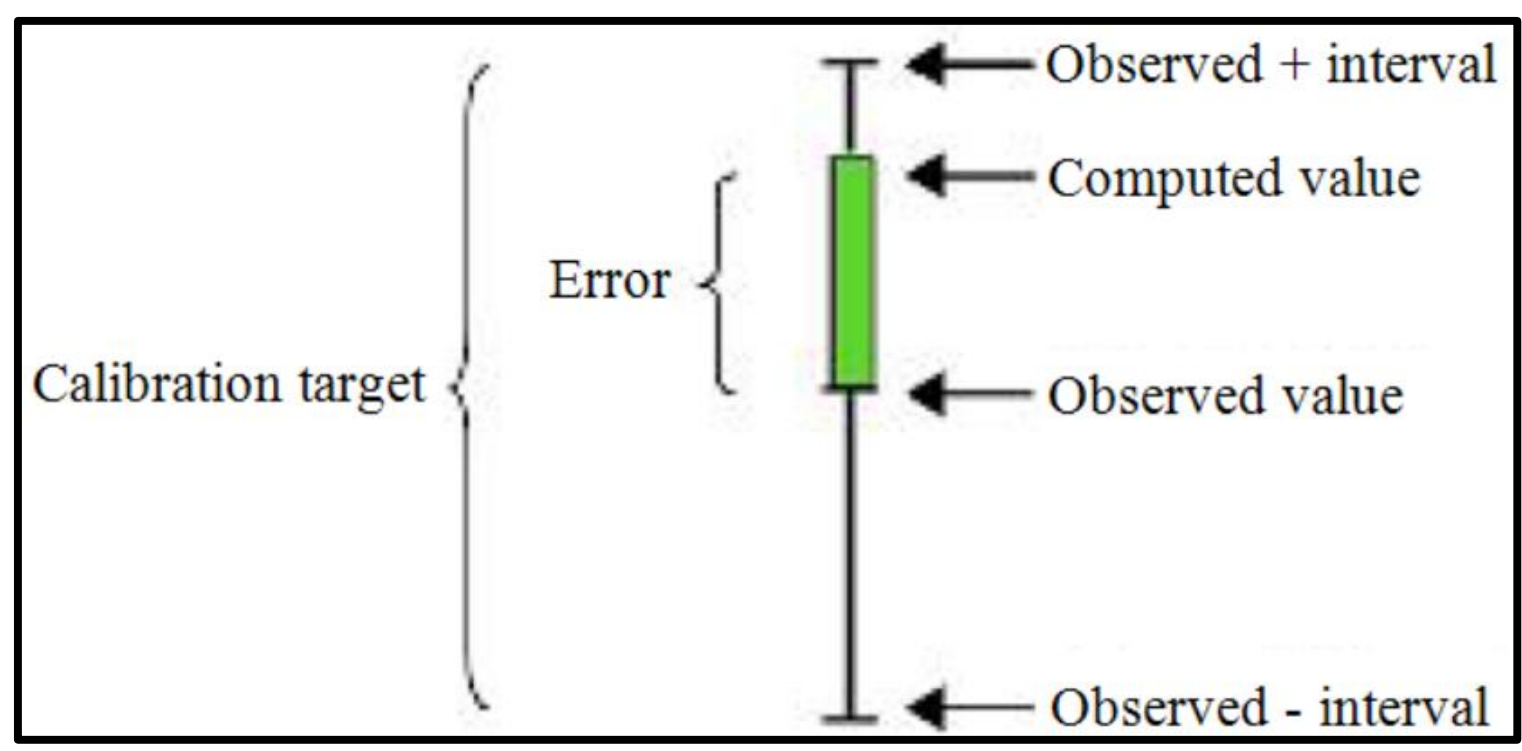

Fig .4. Calibration target [17]

After calibrating process, a good match between observe and simulated values with little variance in the groundwater levels. The mean error and mean absolute error that obtained after model calibrated are equal to $(0.13,0.81)$ respectively. This reflects the model compatibility of the study area as demonstrate in Table (2), and Figures 5, 6 and 7. 
Table 2 Observed and simulated head values at pivot points

\begin{tabular}{|c|c|c|c|c|c|}
\hline \multicolumn{2}{|c|}{ Cell } & \multirow{2}{*}{$\begin{array}{l}\text { Observed } \\
\text { Head (m) }\end{array}$} & \multirow{2}{*}{$\begin{array}{l}\text { Computed } \\
\text { Head (m) }\end{array}$} & \multirow{2}{*}{$\begin{array}{c}\text { Residual Head } \\
\qquad \Delta \mathbf{H}(\mathbf{m})\end{array}$} & \multirow{2}{*}{$\begin{array}{c}\text { Error } \\
\%\end{array}$} \\
\hline I & $\mathbf{J}$ & & & & \\
\hline 81 & 133 & 46.47 & 46.27521 & 0.19479 & 0.42 \\
\hline 81 & 132 & 46.6 & 46.25399 & 0.34601 & 0.75 \\
\hline 81 & 132 & 46.47 & 46.2234 & 0.2466 & 0.53 \\
\hline 82 & 133 & 46.45 & 46.1884 & 0.2616 & 0.57 \\
\hline 104 & 135 & 44 & 43.76337 & 0.23663 & 0.54 \\
\hline 104 & 136 & 44 & 43.79653 & 0.20347 & 0.46 \\
\hline 169 & 145 & 42.46 & 42.21478 & 0.24522 & 0.58 \\
\hline 169 & 145 & 42.53 & 42.21988 & 0.31012 & 0.73 \\
\hline 169 & 145 & 42.53 & 42.21973 & 0.31027 & 0.73 \\
\hline 169 & 144 & 42.28 & 42.18312 & 0.09688 & 0.22 \\
\hline 109 & 96 & 42.116 & 42.84712 & -0.73112 & 1.70 \\
\hline 107 & 97 & 42.72 & 42.91203 & -0.19203 & 0.45 \\
\hline 103 & 96 & 42.585 & 42.96831 & -0.38331 & 0.89 \\
\hline 117 & 123 & 42.28 & 42.65816 & -0.37816 & 0.88 \\
\hline 117 & 123 & 42.96 & 42.65715 & 0.30285 & 0.71 \\
\hline 120 & 123 & 42.505 & 42.55924 & -0.05424 & 0.13 \\
\hline 122 & 124 & 42.94 & 42.49686 & 0.44314 & 1.04 \\
\hline 123 & 122 & 42.62 & 42.50285 & 0.11715 & 0.28 \\
\hline 164 & 79 & 41.49 & 41.61379 & -0.12379 & 0.29 \\
\hline 155 & 80 & 41.68 & 41.86333 & -0.18333 & 0.44 \\
\hline
\end{tabular}




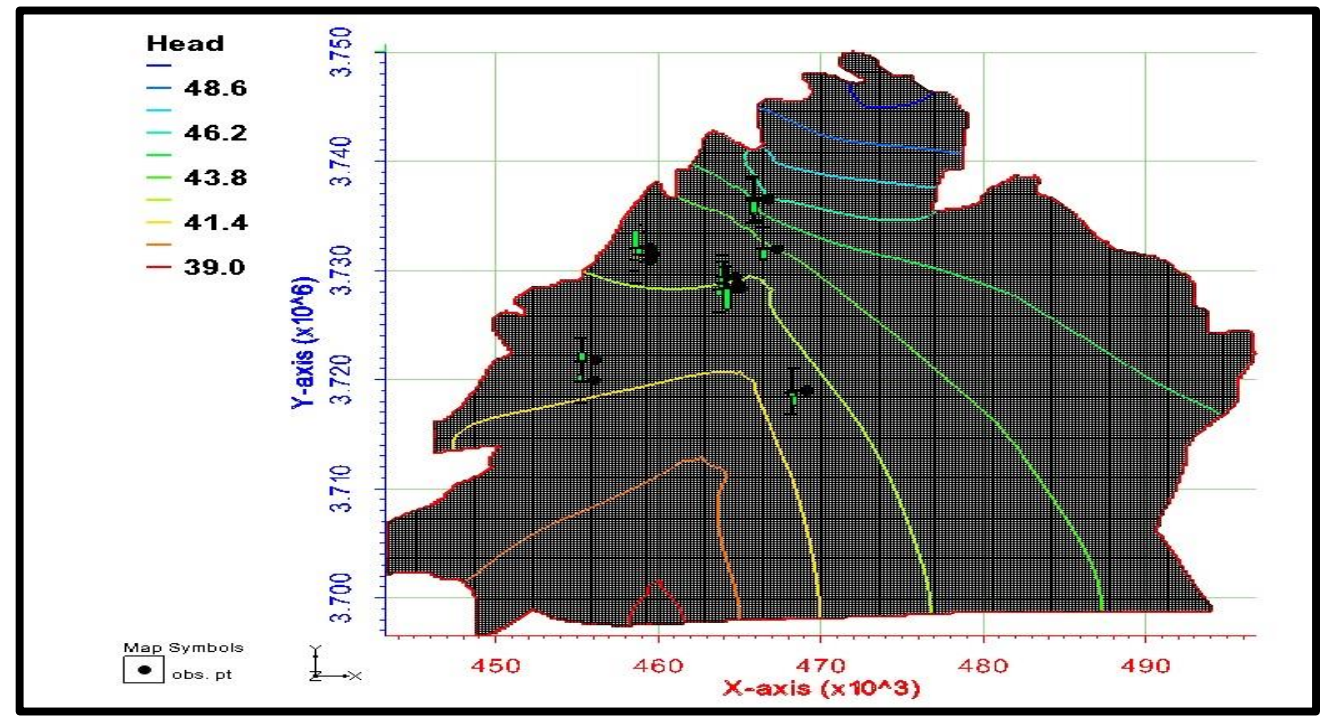

Fig .5. Distribution of simulated groundwater heads of the study area

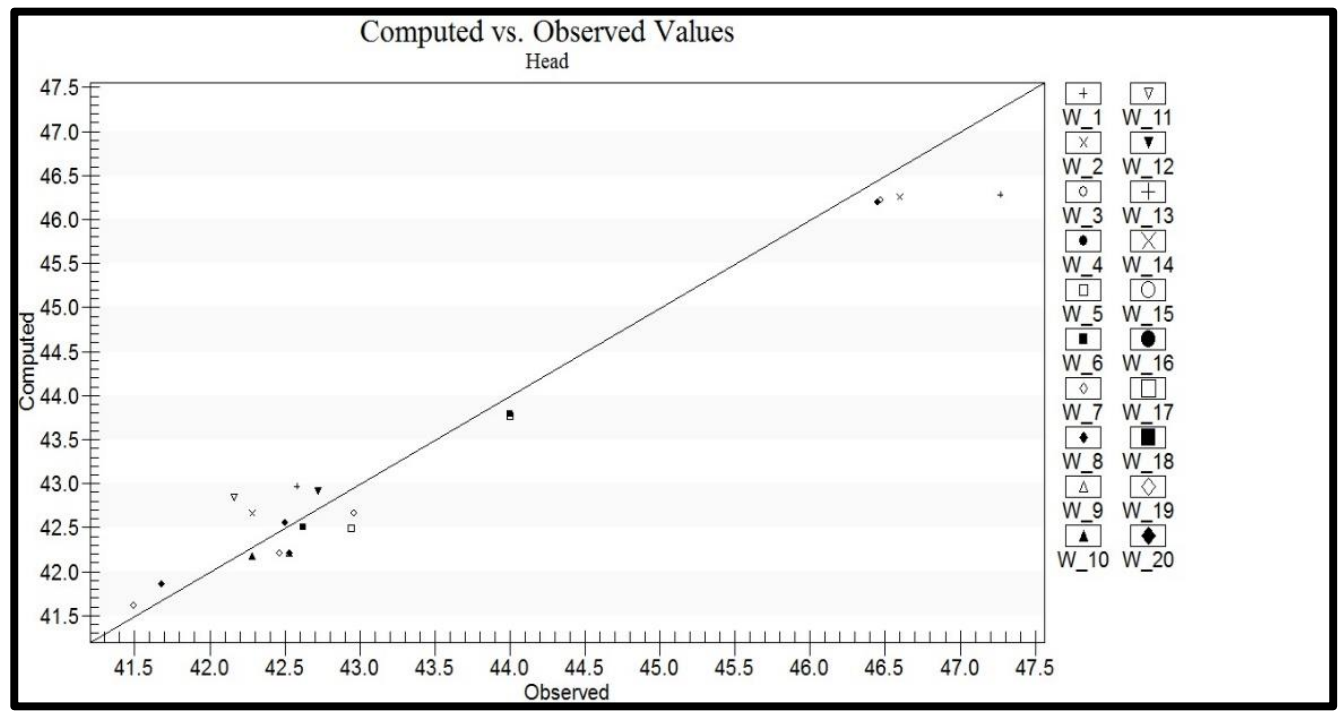

Fig (6) Simulated versus observed values after calibration

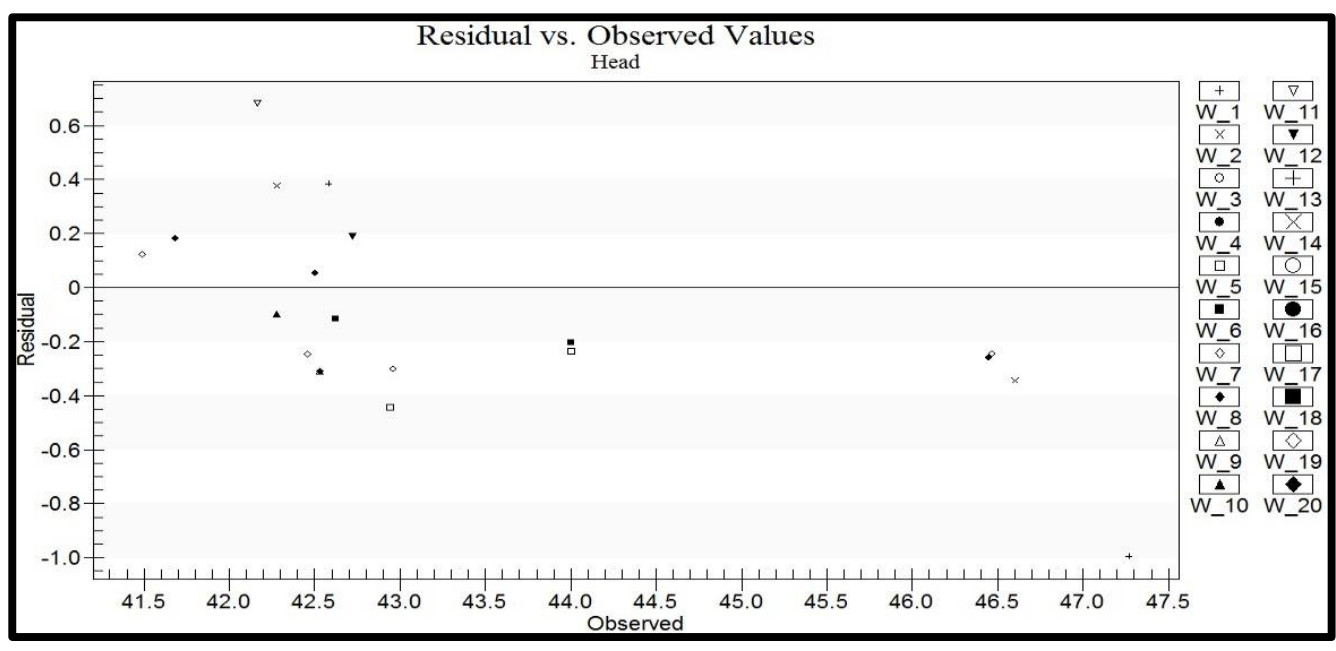

Fig. 7. Residual versus observed values after calibration 


\section{Model sensitivity analysis}

Many reasons have caused uncertainty of the groundwater model which includes aquifer parameter, the boundary condition of the model etc. This uncertainty is measured by the criteria of the model sensitivity analysis. The concept that the sensitivity analyses have based on it is choosing the most sensitive parameter for the model implementation by systematically changing the parameter resulted from calibration process in order to determine what parameter need more attention in the future studies [18]. In this study the sensitivity analysis has been an attempt by changing values of recharge and hydraulic conductivity and all the changing is an attempt systematically. The key values have associated with each of the hydraulic conductivity and recharge zones are shown on the polygons in Figure 8. The relationship between the key values of hydraulic conductivity and recharge rates with the sensitivity values shown in Figures 9 and 10.

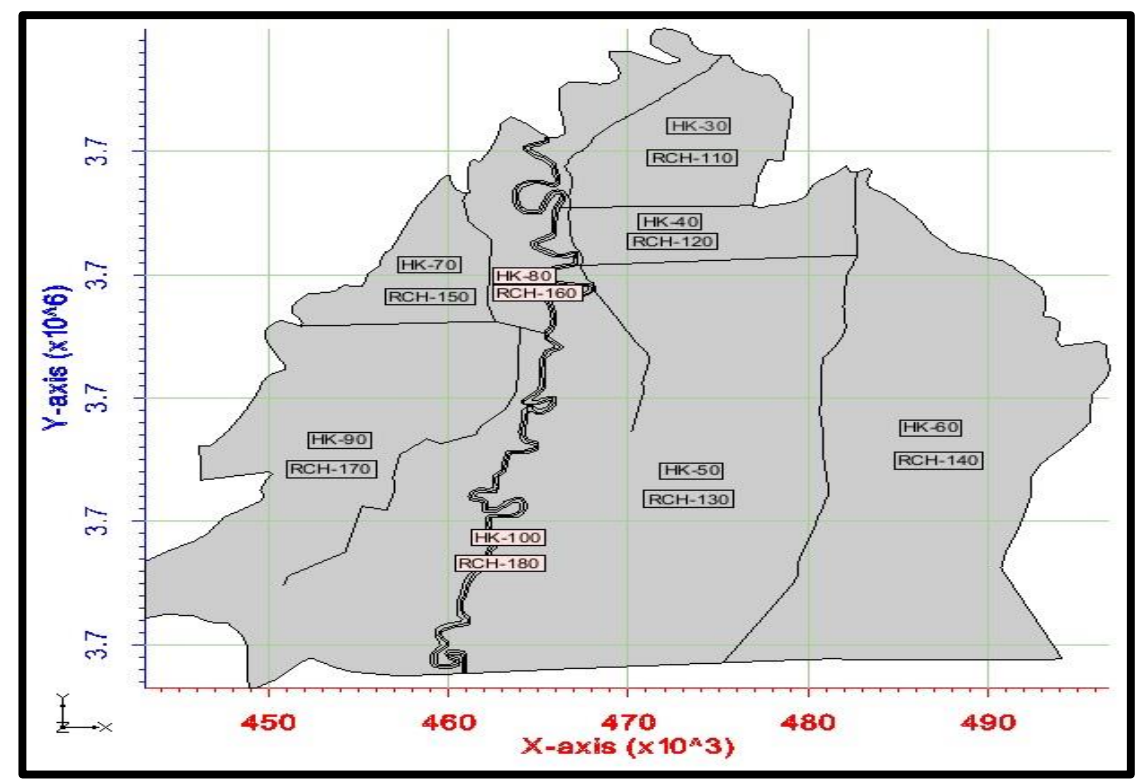

Fig. 8. Hydraulic conductivity and recharge zones with parameters key values

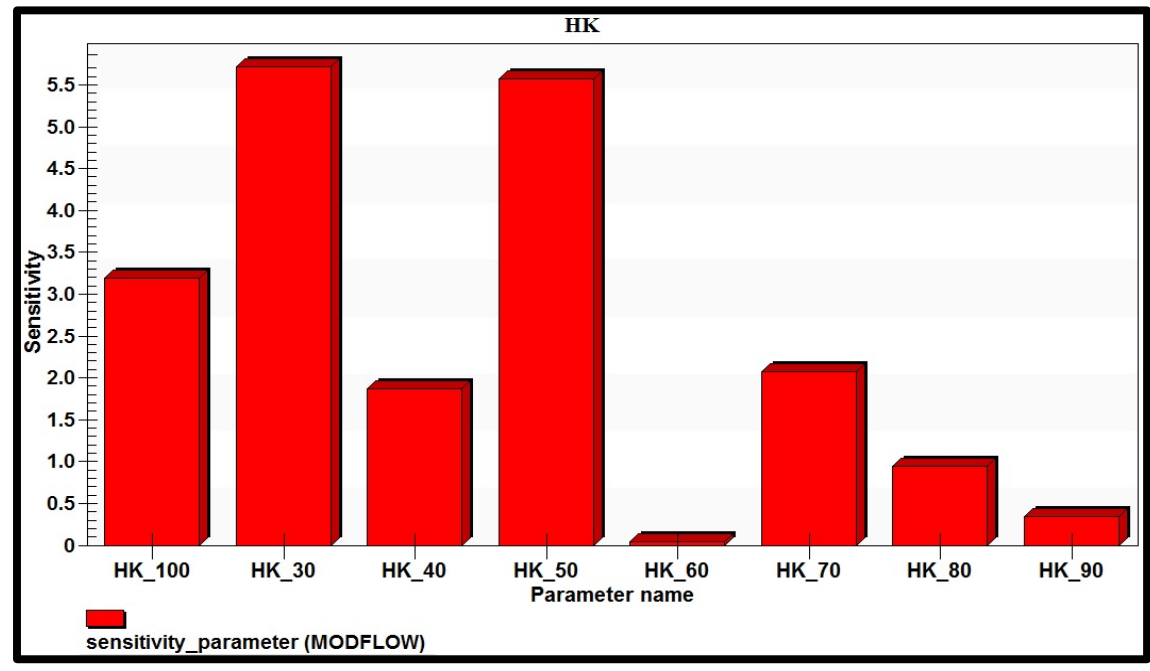

Fig. 9. Hydraulic conductivity versus sensitivity values 


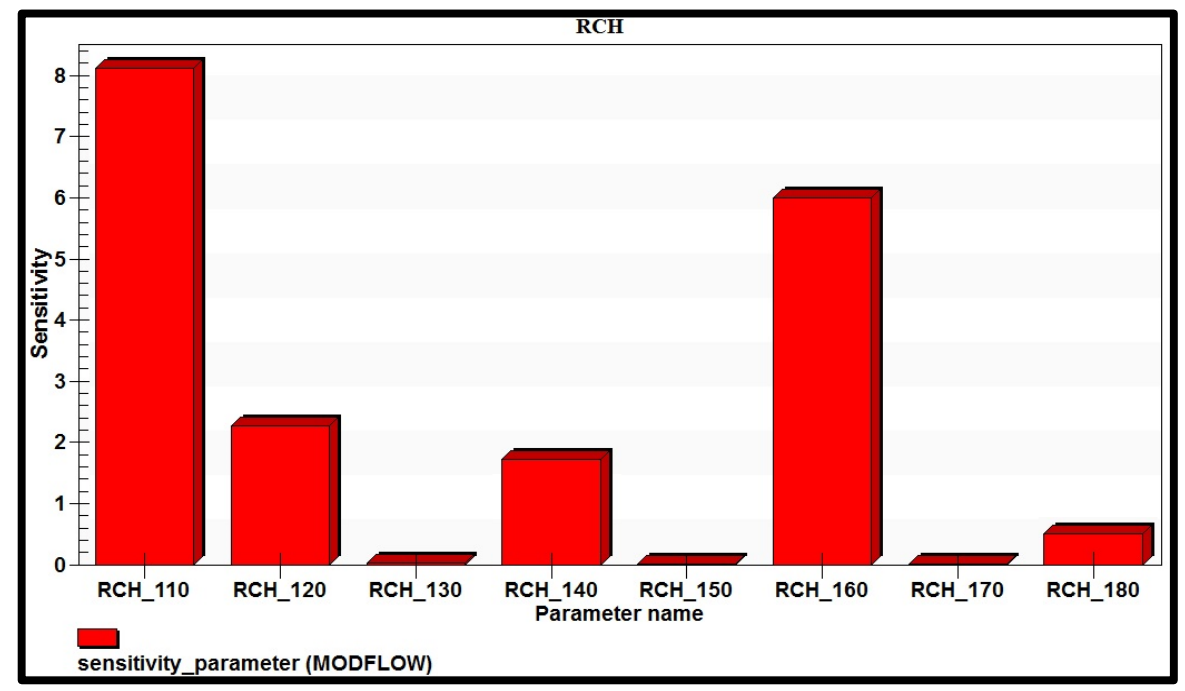

Fig. 10. Recharge rate versus sensitivity values

\section{Applying different scenarios}

The scenarios have been used to predict the aquifer drawdown in the study area are equal to six through the period extends from (2018-2027) with ten-time steps subdivision. According to this manner, the head can be computed and mapped at any time through the extended period. The constant rates of pumping have been assumed in the first scenario. And the pumping rates have been assumed to be increase with percentage $25 \%, 50 \%, 75 \%$, and $100 \%$ successively in 2nd, 3rd, 4th, and 5th scenarios respectively. Finally, propose scenario (6th) agricultural land with drilling new wells within Al-Bardia area which has a high groundwater supply quantity (see Table 3). These are demonstrated as follows:

Table 3 Cases of pumping schedule that examined in GMS-MODFLOW

\begin{tabular}{|l|c|c|c|c|}
\hline Cases & Recharge mm/day & $\begin{array}{c}\text { Boundary } \\
\text { Condition }\end{array}$ & $\begin{array}{c}\text { Applied Pumping Rate } \\
\mathbf{m 3 / d a y}\end{array}$ & $\begin{array}{c}\text { Applied Pumping Rate } \\
\text { Value m3/day }\end{array}$ \\
\hline Case 1 & Not Change & Not Change & Current & 36451.5 \\
\hline Case 2 & Not Change & Not Change & Increased up to 25\% & 54564.3 \\
\hline Case 3 & Not Change & Not Change & Increased up to 50\% & 63790.1 \\
\hline Case 4 & Not Change & Not Change & Increased up to 75\% & 72902.9 \\
\hline Case 5 & Not Change & Not Change & Increased up to 100\% & 72902.9 \\
\hline Case 6 & Not Change & Not Change & $\begin{array}{c}\text { Current + new wells } \\
\text { discharge }\end{array}$ & \\
\hline
\end{tabular}

First scenario: The first scenario has been applied to study the influence of the current discharge rate $(1.3 \times 106 \mathrm{~m} 3 /$ year $)$ of the drilled wells in the city of Baquba which have 120 wells. Under these stresses, the model has been run and the estimated head have been examined for each time steps (next ten years), they are an attempted by the model tool named as the extractor tool belongs to the GMS program as shown in Figure (11). In the present case, it can be observed the maximum drawdown value that record in the next ten years reach about $11.426 \mathrm{~m}$. As well as a good agreement has been getting between the values of the safe yield that compute 
from steady-state calibration and the present scenario discharging rates, therefore the drying cells not appear, as well as these indicate the possibility to increasing withdrawal rate or drilling new wells.

\begin{tabular}{|c|c|c|c|c|c|c|c|c|c|c|}
\hline \multirow[t]{2}{*}{ Time step: } & \multicolumn{10}{|c|}{$\nabla$ Show all time step stats. } \\
\hline & & & & & & & & & & \\
\hline Time step number: & 1 & 2 & 3 & 4 & 5 & 6 & 7 & 8 & 9 & 10 \\
\hline Time: & 365.0 & 730.0 & 1095.0 & 1460.0 & 1825.0 & 2190.0 & 2555.0 & 2920.0 & 3285.0 & 3650.0 \\
\hline Min value: & -5.85111 & -5.67342 & -5.53962 & -5.42468 & -5.32207 & -5.22669 & -5.13968 & -5.05817 & -4.98216 & -4.90962 \\
\hline Max value: & 7.407847 & 8.218489 & 8.396579 & 8.466096 & 8.506803 & 8.7623 & 9.446139 & 10.10404 & 10.7558 & 11.42615 \\
\hline Range: & 13.25896 & 13.89191 & 13.9362 & 13.89078 & 13.82887 & 13.98899 & 14.58582 & 15.16221 & 15.73797 & 16.33577 \\
\hline Mean: & -0.7278058 & -0.4894523 & -0.2980479 & -0.1292889 & 0.0243557 & 0.1662499 & 0.299638 & 0.427048 & 0.5498392 & 0.6688162 \\
\hline Median: & -0.4231824 & -0.2151181 & -0.06033281 & 0.06359804 & 0.1815042 & 0.2980189 & 0.4081632 & 0.5077726 & 0.6092293 & 0.7081085 \\
\hline Standard deviation: & 1.217482 & 1.267477 & 1.312482 & 1.354939 & 1.396336 & 1.436929 & 1.476881 & 1.515907 & 1.553972 & 1.591067 \\
\hline
\end{tabular}

Fig. 11. GMS windows showed the drawdown analyzed values in each time step

Second scenario: In this scenario the current withdrawal rates will be increased by $25 \%$. The maximum drawdown value that recorded in the next ten years reached about $11.938 \mathrm{~m}$. In this scenario, it can be noticed that there is good agreement between the safe yield which was calculated from the steady-state calibration and this scenario abstraction rate. In this case also the drying cells not appeared these indicate the discharge rates can be increased or adding new wells.

Third scenario: In this Scenario, the current pumping rates will be increased by $50 \%$. In this case, the maximum value of the drawdowns that notes for the period (next10 years) is equal to (12.246m).

Fourth scenario: The withdrawal rates in this scenario will be increased by about $75 \%$, from the current discharging rates. The maximum drawdown value has been noticed is equal to $13.361 \mathrm{~m}$.

Fifth scenario: In the scenario (5th), the abstraction rates will be increased by about $100 \%$, above the current withdrawal rates. In this case, the maximum drawdown value that has been noticed is equal to $14.05 \mathrm{~m}$, as well as no drought in the cells that appeared.

Sixth scenario: In the last scenario, drilling twenty wells within Al-Bardia area to investment agricultural land. The net distance between well is equal to $400 \mathrm{~m}$, therefore the total project area equal to $2.52 \mathrm{~km} 2$. The abstraction rate of the new drilling well has assuming equal to $432 \mathrm{~m} 3 /$ day. The new wells have run with the current wells that locate within the study area that applied in the first scenario. The drawdown map distribution is shown in Figure 12. The maximum drawdown value that recorded in this scenario was equal to $11.87 \mathrm{~m}$. 




Fig. 12. Drawdown map distribution at the new wells

\section{Conclusions}

From the present study the following conclusions are derived:

1. The model calibration process results has showed a good agreement between computed and observed head values as well as the sensitivity parameter analysis indicated that the hydraulic conductivity and recharge rate in some places are more sensitive than other places, but the storage coefficient is an insensitive parameter.

2. The maximum annual values of the drawdown for the next ten years according to the five scenarios are equal to $(11.426,11.938$, $12.246,13.631$, and 14.05)m respectively, while the drawdown value for the sixth scenario (proposed) is equal to $11.87 \mathrm{~m}$.

3. The results of the model reflect that the maximum values of the drawdown for the two regions of (Kanan and Buhriz) are very large, and according to this reason the management program is very important for dealing and manage the groundwater extraction in these regions.

\section{References}

[1] Jalut, Qassem H., and Anmar S. Saleh. "Evaluation of conjunctive water use impacts on soil hydraulic properties and root water uptake using HYDRUS-3D model." 2018 1st International Scientific Conference of Engineering Sciences-3rd Scientific Conference of Engineering Science (ISCES). IEEE, 2018.
[2] Jalut, Qassem H., Nadia L. Abbas, and Abdulrahman Th Mohammad. "Management of groundwater resources in the Al-Mansourieh zone in the Diyala River Basin in Eastern Iraq." Groundwater for Sustainable Development 6 (2018): 79-86.

[3] Jalut, Qassem Hamed, and Daniel F. Sunada. Conjunctive use model of groundwater and surface water in irrigation command area. Colorado State University, Groundwater Program, Department of Civil Engineering, 1989.

[4] Kumar, C. P. 2015. Modelling of groundwater flow and data requirements. International Journal of Modern Sciences and Engineering Technology 2(2), pp. 18-27.

[5] Olayinka, S. (2013). Assessing the importance of geo-hydrological data acquisition in the development of sustainable water resources framework in Nigeria. Journal of Environmental and Earth Science, 3 (14), 1-10.

[6] Karamouz, M., Szidarovszky, F. and ZahraieWater, B. (2003). Water Resources Systems Analysis. Lewis Publishers, USA.

[7] Mall, R., Gupta, A., Singh, R., Singh, S. and Rathore, L. (2006). Water resources and climate change: An Indian perspective. Curr. Sci., 90: 1225.

[8] Kumar, C.P. (2013). Numerical modelling of groundwater flow using MODFLOW. Indian Journal of Science, 2(4): 86-92.

[9] McDonald, M.G. and Harbaugh, A.W., 1988. A modular three-dimensional finite-difference ground-water flow model (Vol. 6, p. A1). Reston, VA: US Geological Survey.

[10] Harbaugh, A. W., Banta, E. R., Hill, M. C. and McDonald, M.G. (2000). MODFLOW-2000. The U.S. Geological Survey Modular GroundWater Model - User Guide to Modularization Concepts and the Ground-Water Flow Process, USGS Open-File Report 00-92. 
[11] Mohammad Amaar Hassan and Dr. Qassem H. Jalut, Mathematical Modeling of Rainwater Harvesting System for Ungauged Catchment Area, International Journal of Civil Engineering and Technology, 9(11), 2018, pp. 823-837

[12] Al-Jiburi, Hatem K., and Naseer H. Al-Basrawi. "Hydrogeology of the Mesopotamia Plain." Iraqi Bulletin of Geology and Mining 4 (2011): 1-21.

[13] Jalut, Qassem H., and Fatan R. Majeed. "Hydrochemical analysis of groundwater resources in Kanan region." DIYALA JOURNAL OF ENGINEERING SCIENCES 8.4 (2015): 74-82.

[14] Abdullah, Thair H., Qassem H. Jalut, and Yousif W. Ameen. "Hydrologic Modeling for Sedimentation in Hemrin Reservoir Using HEC-HMS." DIYALA JOURNAL OF ENGINEERING SCIENCES 11.4 (2018): 67-72.

[15] Ghodoosipour, Behnaz. "Three dimensional groundwater modeling in Laxemar-Simepevarp guaternary deposits." (2013).

[16] Prickett, Thomas A., and Carl G. Lonnquist. "Selected digital computer techniques for groundwater resource evaluation." Bulletin (Illinois State Water Survey) no. 55 (1971).

[17] EMS-I, 2005. Groundwater Modeling System, Environmental Modeling Systems, Inc., http://www.emsi.

com/GMS/GMS_Overview/gms_overview.html on 2006-10-01 Environmental Modeling Research Laboratory, 1999. Groundwater Modeling SystemGMS Reference Manual. ftp://ftp.gtk.fi/mirrors/gms/gms/gms3.0/docs/refma n30.pdf.

[18] Anderson, M. and Woessner, W. 1992. Applied groundwater modeling: Simulation of Flow and advective transport. San Diego, California: Academic Press Inc. 